\title{
Earthquake resistance of a historical brick building in Akita Prefecture, Japan
}

\author{
C. Cuadra, K. Tokeshi, M. B. Karkee \& Y. Sakaida \\ Graduate School of System Science and Technology, \\ Department of Architecture and Environment Systems, \\ Akita Prefectural University, Tsuchiya, Honjo, Akita, Japan
}

\begin{abstract}
During the Meiji period (by the end of the $19^{\text {th }}$ century) many brick masonry buildings were constructed in Japan. However, due to the lack of reinforcement these structures collapsed during the great Kanto earthquake, which occurred in the year 1923. Since then, this type of structure is not used for buildings and only a few historical constructions remain from that era. In Akita Prefecture, in the northeastern part of Japan, some of these buildings have been declared as local culture heritages. One of them is located in Ani village and was constructed in 1879 to serve as the residence for a German engineer who was working for a local mining company. As an initial step to evaluate the seismic vulnerability of this historical building, dynamic characterization has been undertaken. For that purpose, measurements of the micro vibration of the building was planned and undertaken by the authors. For the analytical modeling, mechanical parameters were estimated from a series of laboratory tests on masonry brick units obtained from the stock that are conserved near the building under study. The results of the microtremor measurements are discussed in relation to the analytical procedure adopted to estimate the dynamic characteristics of this historical brick structure. The structure shows intricate modes of vibration that are reflected in the multiple peaks observed in the transfer functions of microtremor records. With the analytical simulation considering only the effect of the brick walls, the multiple predominant frequencies are obtained for a certain range. With this good agreement of the analytical procedure and the measurement results, the reliability of the employed methodology was verified.

Keywords: masonry building, dynamic behaviour, microtremor measurements, finite element method, mode analysis.
\end{abstract}




\section{Introduction}

The masonry buildings are used widely around the world. In Japan during the Meiji period, the number of builders that used masonry increased and the masonry structures became a common technology for construction. However, due to its poor seismic performance, especially during the great Kanto earthquake at the beginning of the $20^{\text {th }}$ century, the technology was abandoned and was replaced by reinforced concrete structures. Therefore, only a few masonry constructions remain at present, and have become historical constructions.

Some of these buildings are located in the northern part of Japan, specifically in Akita Prefecture, and most of them have been declared local cultural heritage. One of these buildings, the object of this study, is the house of a former mining engineer who was the superintendent in Ani village.

In recent years, each region, city or town of Japan has been active to show their particularities, especially, in history and local cultural aspects. If some masonry buildings are located in these zones, then they are included in these activities and therefore, it is necessary to consider the restoration and conservation of these buildings. For this purpose, the evaluation of their seismic behavior and vulnerability is needed. Then, if it is required, the correspondent proposal for their conservation, reparation or restoration can be done. In Japan, the study of these types of buildings is essential since there are not specific regulations for masonry, and only a few researches are done in the area of masonry constructions.

In this research, an attempt is made to evaluate the seismic performance of a historical masonry building located in Akita Prefecture, in the northeastern part of Japan. The methodology for the seismic vulnerability evaluation is based on microtremor measurements to estimate the vibration characteristics of the building. Then, structural analysis is performed to compare the results with those obtained experimentally.

\section{Description of the building object of the present study}

The building, object of this study, is located in Ani village in Akita Prefecture and it was constructed during the $12^{\text {th }}$ year of the Meiji period (year 1879). It was constructed to be the house of Adolf Mecker, a German engineer that came to Japan to work in the mines of the Akita region. As can be observed in figure 1, the main structure is formed by the masonry walls and complemented by a wooden structure that forms a kind of fence around the building. The architectural style corresponds to the Gothic Renaissance with some arches to form the windows and doors openings. The masonry units were fabricated with clay of the zone and burned in a factory constructed for that specific purpose. The design and the direction of the construction of the house were done by Mr Mecker himself. 
After finishing his employment contract, Mr Mecker returned to his country and the house was used first as a government office, and then as a social club for the mining workers.

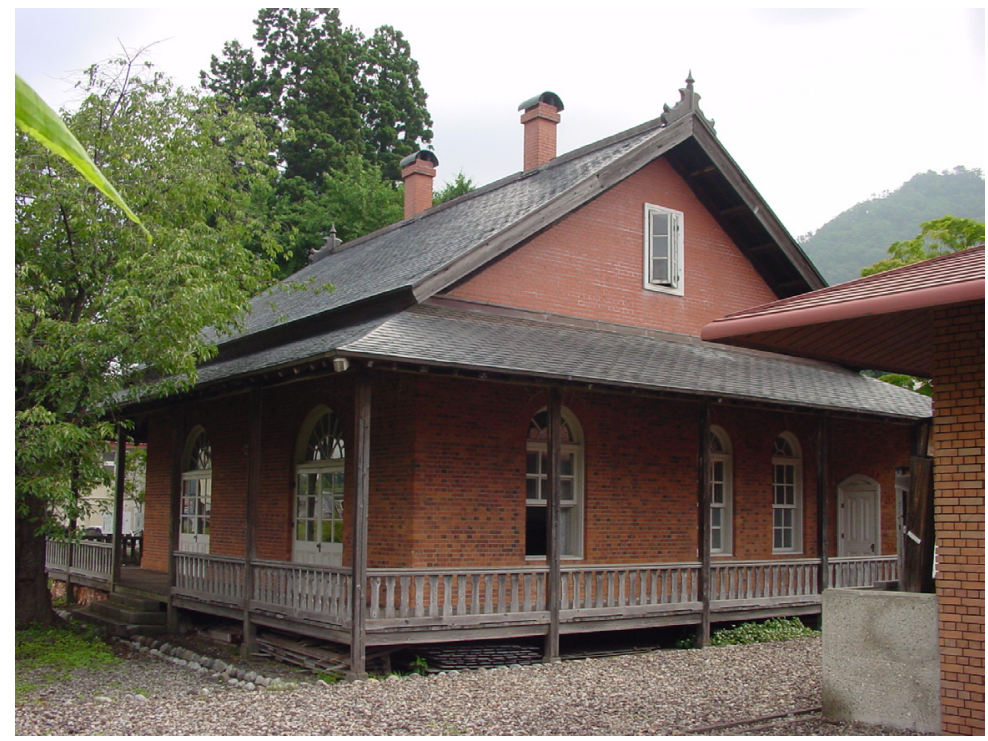

Figure 1: $\quad$ Building object of the study.

The building under study, has suffered the action of some earthquakes, and the most recent was the Moriyoshiyama earthquake in the year 1982. This earthquake was a near source earthquake and partially destroyed the building. The Prefecture government reconstructed the building replacing the triangular gabble wall of the second story by light material instead of clay brick masonry. Then only the first floor walls remain with the original dimensions and with clay brick lied with cement mortar.

The building was designated as prefecture cultural heritage in the year 1956, and recently in the year 1990, was recognized as Japanese national cultural heritage.

\section{Measurements of the micro vibrations}

Figure 2 shows the plan distribution of the building, where the sensors were located in the following arrangement for the first set of measurements: one sensor at the first floor (1), five sensors at the second floor level $(2,3,4,5,6)$ and one on the ground (7). For a second set of measurements, the sensors 2 and 7 were located at the top of the central beam of the roof. These points of measurement were called 2' and 7'. The measurement of microtremors were measured in the three principal directions (east-west (EW), north-south (NS) and 

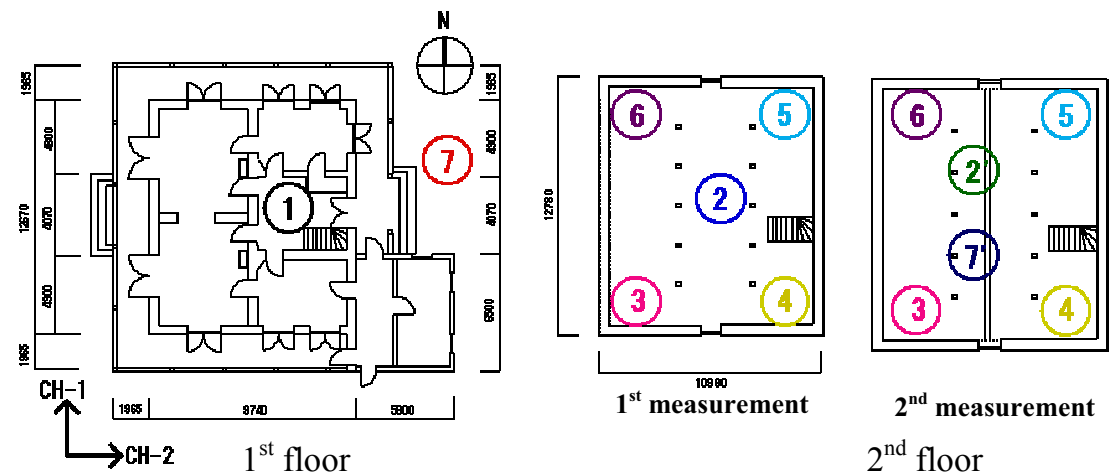

$2^{\text {nd }}$ measurement

$2^{\text {nd }}$ floor

Figure 2: $\quad$ Points of microtremor measurements.
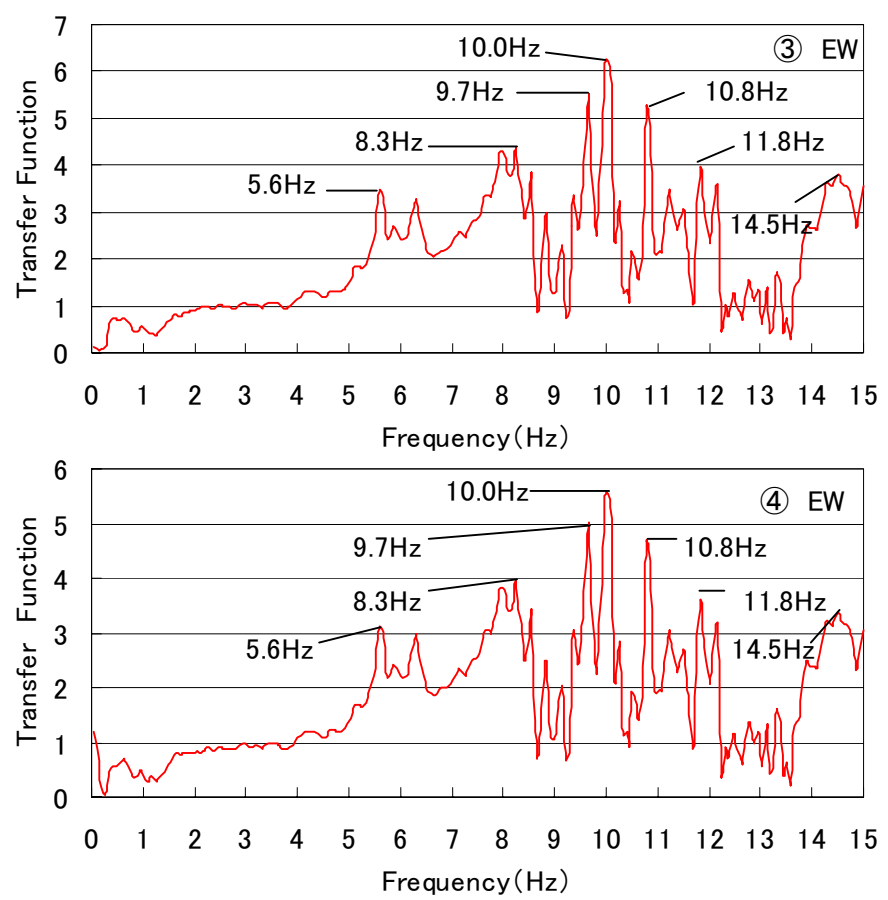

Figure 3: Transfer function results for EW direction.

up-down (UD)) at each point. The micro vibrations were measured simultaneously during 500 seconds with a sampling frequency of $100 \mathrm{~Hz}$. Then, stationary portions of the records were selected to calculate the transfer function that permits to estimate the predominant periods of vibration of the structure. The results of the transfer function for the horizontal vibrations are shown in figure 3 and 4 . The transfer function at each measured point of the structure was divided by 

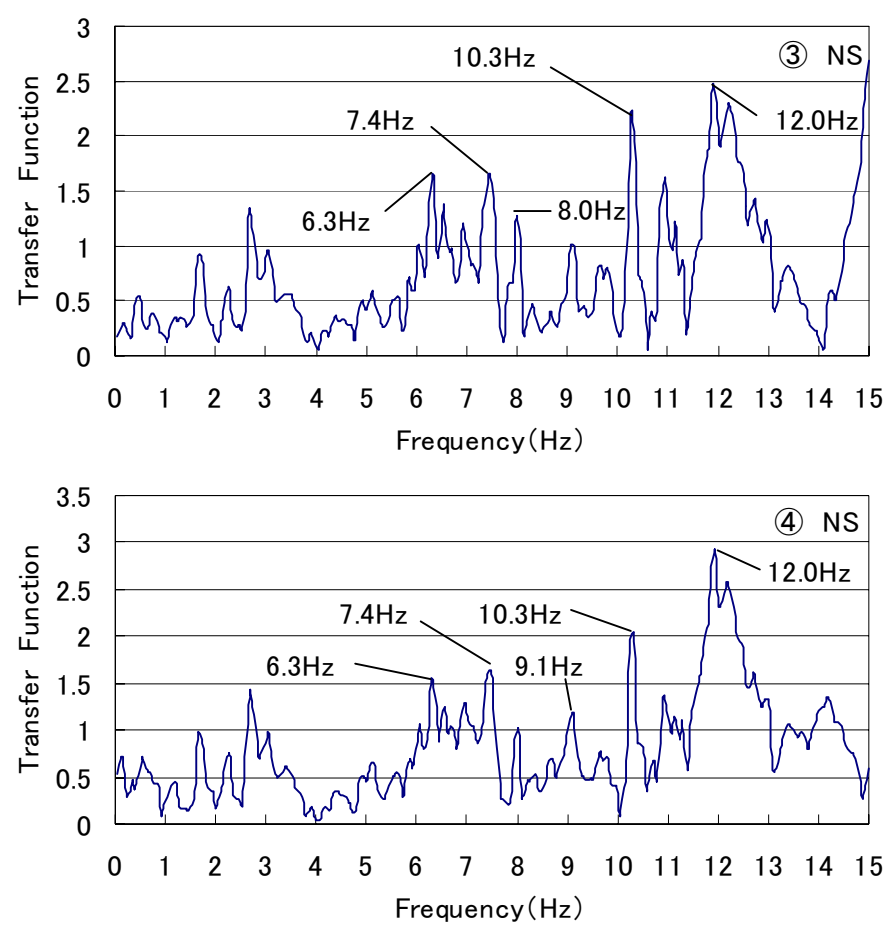

Figure 4: Transfer function results for NS direction.

the one at the first floor level, to only obtain the vibration characteristics of the upper structure. According to these transfer function results, multiple peaks can be observed in such a way that is not possible to obtain only one characteristic frequency. Therefore, the mode of vibration is not a simple horizontal normal mode. Instead of it, the modes of vibration are intricate. These complex modes of vibration can be explained by the concentration of the mass of the structure in the walls instead of in the slab.

\section{Characteristics of brick units}

Brick units selected from those that were stocked near the building were used to determine the physical and mechanical properties of the bricks. From the stock it was difficult to distinguish between those units used in the old construction and those used for the repair works. Independently of this condition, units showing good aspect were selected for the laboratory tests. These units can be observed in figure 5 .

The properties of water suction ratio, density, compression strength and modulus of elasticity were obtained and the average values are presented in table 1 . 

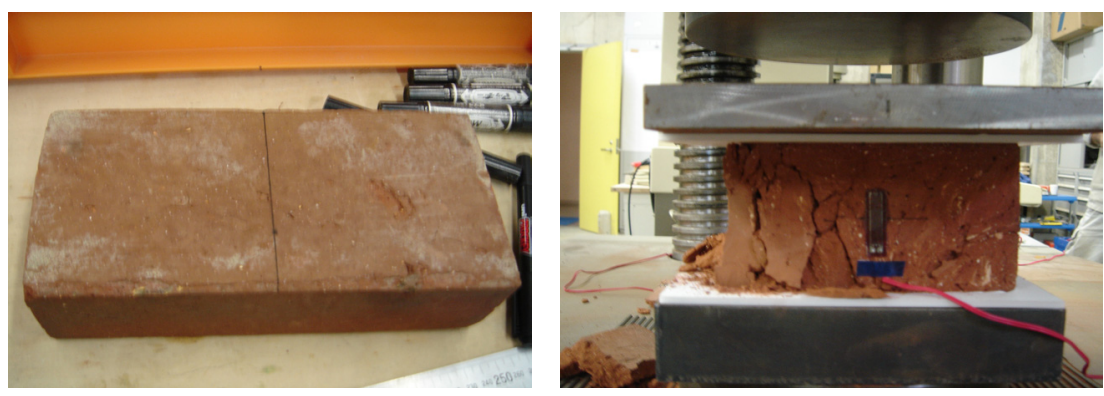

Figure 5: Brick units employed to obtain the physical and mechanical properties.

Table 1: $\quad$ Physical and mechanical properties of brick units.

\begin{tabular}{|c|c|c|c|}
\hline Suction ratio (\%) & Density $\left(\mathrm{gr} / \mathrm{cm}^{3}\right)$ & $\begin{array}{c}\text { Compression } \\
\text { strength } \\
\left(\mathrm{N} / \mathrm{mm}^{2}\right)\end{array}$ & $\begin{array}{c}\text { Young Modulus } \\
\left(\mathrm{N} / \mathrm{mm}^{2}\right)\end{array}$ \\
\hline 24 & 1.64 & 12 & $1.06 \times 10^{4}$ \\
\hline
\end{tabular}

\section{FEM modelling}

In order to compare the measurement results with analytical procedure, a Finite Element Model (FEM) was constructed considering only the brick masonry walls. This assumption is done with the intention of obtain the influence of the mass of the walls on the modes of vibration. Here it is assumed that the wall, including the mortar has homogenous properties and they are equal or similar to that obtained for the brick units. The model was constructed referring to the available plans and direct measurements of the building. In total, 280 parallelepiped solid elements were used. The complete model is displayed in figure 6 .

The 10 first modes of vibration were obtained from the tri-dimensional analysis in which frequencies varied from $8.3 \mathrm{~Hz}$ to $12.6 \mathrm{~Hz}$. By comparing these with the results of the microtremor measurements, a good agreement is observed in the modes of vibration detected as a peak in the transfer functions. In tables 2 and 3 the comparison of the predominant frequencies obtained from measurements with analytical results are presented for EW and NS directions, respectively. The right column indicates the measurement point in which the predominant frequency was observed. The finite element method result shows in parenthesis the order of the mode of vibration obtained from the 3D analysis. As an illustrative example, the first 2 modes of vibrations are shown in figure 7. 


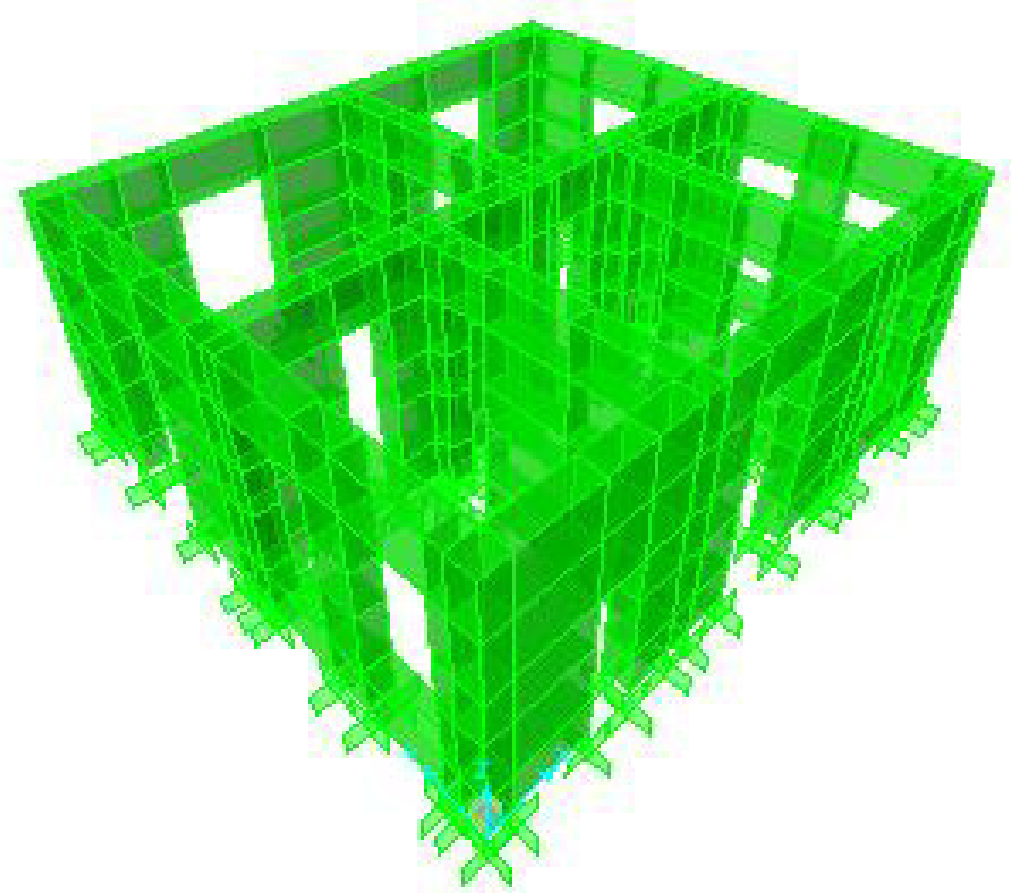

Figure 6: $\quad$ FEM model.

Table 2: Comparison of measured frequencies and FEM results (EW direction).

\begin{tabular}{|c|c|c|}
\hline $\begin{array}{c}\text { Microtremor } \\
\text { measurements }(\mathrm{Hz})\end{array}$ & FEM analysis $(\mathrm{Hz})$ & Point of measurement \\
\hline 8.3 & $8.3($ mode 1$)$ & $2^{\prime}, 3,4,5,6,7^{\prime}$ \\
\hline 8.8 & $8.8($ mode 2$)$ & 2', 5, 6, 7' \\
\hline 9.2 & $9.3($ mode 4$)$ & $2^{\prime}, 5,6,7^{\prime}$ \\
\hline 10.8 & $10.7($ mode 6$)$ & $3,4,5,6,7^{\prime}$ \\
\hline 11.8 & $11.9($ mode 8$)$ & $3,4,7^{\prime}$ \\
\hline
\end{tabular}

Table 3: Comparison of measured frequencies and FEM results (NS direction).

\begin{tabular}{|c|c|c|}
\hline $\begin{array}{c}\text { Microtremor } \\
\text { measurements }(\mathrm{Hz})\end{array}$ & FEM analysis $(\mathrm{Hz})$ & Point of measurement \\
\hline 9.1 & $9.1($ mode 3$)$ & $3,4,5$ \\
\hline 10.3 & $10.3($ mode 5$)$ & $3,4,5$, \\
\hline 10.9 & $11.1($ mode 7$)$ & $3,4,5,7$ \\
\hline 12.0 & $12.0($ mode 9$)$ & $3,4,5,6$ \\
\hline 12.5 & $12.6($ mode 10$)$ & $2,3,4,5,6,7$ \\
\hline
\end{tabular}


$1^{\text {st }}$ mode

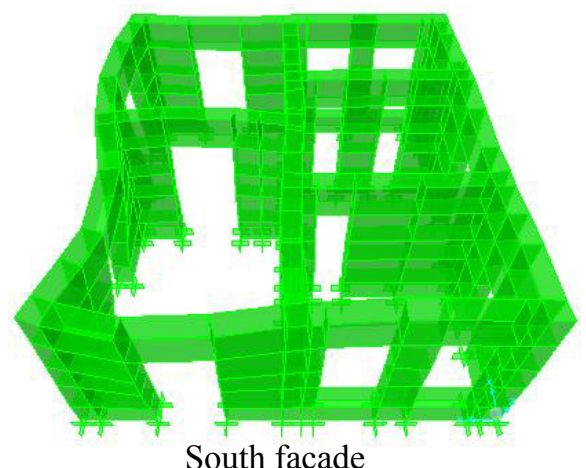

South facade $2^{\text {nd }}$ mode

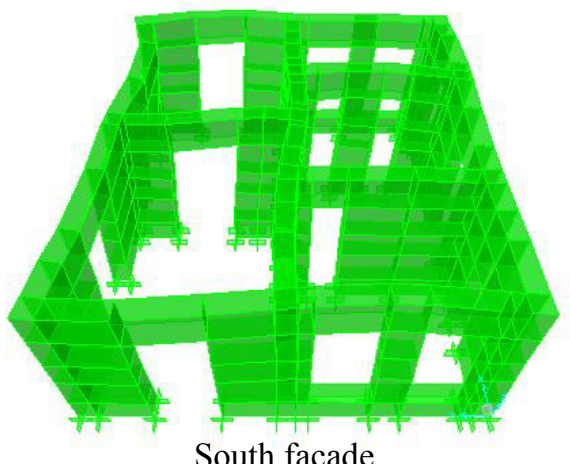

South facade

Figure 7: Analysis results for the first 2 modes of vibration.

\section{Conclusions}

From the micro vibration measurements, several predominant frequencies were obtained from the transfer functions. According to these results, it can be assumed that the building presents an intricate shape of vibration.

To perform the analysis, first the mechanical and physical properties of the brick units were estimated from laboratory tests. These properties have a great dispersion in their values, but these values range between the usual values for clay bricks.

The structural analysis was performed based on the properties of bricks and considering only the walls of the building, since they concentrate the main part of structure mass, and therefore they have a great influence in the shape of vibration. Results show that there is a good agreement between the observed frequencies and those obtained analytically in the range of $8.3 \mathrm{~Hz}$ to $12.6 \mathrm{~Hz}$.

Microtremor measurements combined with FEM analysis provided a valuable basis for the evaluation of the dynamic characteristics of heritage masonry structures.

\section{References}

[1] J. Kanai, K. Tokeshi, C. Cuadra, and M.B. Karkee. Vibration characteristics of buildings using microtremor measurements. First European Conference on Earthquake Engineering and Seismology (a joint event of the $13^{\text {th }}$ ECEE \& $30^{\text {th }}$ General Assembly of the ESC), Geneva, Switzerland, 3-8 September 2006, Paper Number: 708.

[2] C. Cuadra, Y. Sato, J. Tokeshi, H. Kanno, J. Ogawa, M. B. Karkee \& J. Rojas. Evaluation of the dynamic characteristics of typical Inca heritage structures in Machupicchu. Ninth International Conference on Structural Studies, Repairs 
and Maintenance of Heritage Architecture, STREMAH IX, Malta, Jun. 2005, pp. 237-244.

[3] J. Ogawa, C. Cuadra, M.B. Karkee, and J. Rojas. A study on seismic vulnerability of Inca's constructions. Proceedings of the 4th International Conference on Computer Simulation in Risk Analysis and Hazard Mitigation. Risk Analysis IV, Rhodes, Greece 2004, pp 3-12.

[4] C. Cuadra, M.B. Karkee, J. Ogawa, and J. Rojas. Preliminary investigation of earthquake risk to Inca's architectural heritage. Proceedings of the Fourth International Conference of Earthquake Resistant Engineering Structures, Ancona, Italy 2003, pp. 167-176. 